\title{
Beyond conflict: exploring the spectrum of human-wildlife interactions and their underlying mechanisms
}

\author{
Saloni Bhatia, Stephen Mark Redpath
}

Kulbhushansingh SURyananshi and Charudut Mishra

\begin{abstract}
Humans have lived alongside and interacted with wild animals throughout evolutionary history. Even though wild animals can damage property, or injure humans and domesticated animals, not all interactions between humans and wildlife are negative. Yet, research has tended to focus disproportionately on negative interactions leading to negative outcomes, labelling this human-wildlife conflict. Studies have identified several factors, ranging from gender, religion, socio-economics and literacy, which influence people's responses to wildlife. We used the ISI Web of Knowledge database to assess quantitatively how humanwildlife interactions are framed in the scientific literature and to understand the hypotheses that have been invoked to explain these. We found that the predominant focus of research was on human-wildlife conflict ( $71 \%)$, with little coverage of coexistence $(2 \%)$ or neutral interactions (8\%). We suggest that such a framing is problematic as it can lead to biases in conservation planning by failing to consider the nuances of people's relationships with wildlife and the opportunities that exist for conservation. We propose a typology of human responses to wildlife impacts, ranging from negative to positive, to help moderate the disproportionate focus on conflict. We suggest that standardizing terminology and considering interactions beyond those that are negative can lead to a more nuanced understanding of human-wildlife relations and help promote greater coexistence between people and wildlife. We also list the various influential factors that are reported to shape human-wildlife interactions and, to generate further hypotheses and research, classify them into 55 proximate (correlates) and five ultimate (mechanisms) factors.
\end{abstract}

Keywords Attitude, behaviour, human-wildlife coexistence, human dimensions, human-wildlife conflict, human-wildlife interactions, wildlife damage

\footnotetext{
SAlOni Bhatia ${ }^{*} \dagger$ (Corresponding author), Kulbhushansingh SuRYaWANSHi ${ }^{*}$ and Charudutt Mishra* Nature Conservation Foundation, 1311, “Amritha”, 12th Main, Vijayanagar 1st Stage, Mysore 570017, India

E-mail saloni86@gmail.com

Stephen Mark Redpath University of Aberdeen, Aberdeen, UK

*Also at: Snow Leopard Trust, Seattle, USA

$\dagger$ Also at: Manipal Academy of Higher Education, Manipal, India

Received 23 October 2018. Revision requested 22 November 2018.

Accepted 20 December 2018. First published online 4 November 2019.
}

Supplementary material for this article is available at https://doi.org/10.1017/So03060531800159X

\section{Introduction}

T umans have a long, complex relationship with wild 1 animals, varying between appreciation, reverence, retaliation, utilization and acceptance (Treves \& NaughtonTreves, 1999; Ingold, 2000; Lescureux \& Linnell, 2010; Ghosal \& Kjosavik, 2015). Studies have tried to understand these relationships by characterizing their nature and by examining the challenges of living with wildlife, especially with species that are responsible for negative impacts such as damage to property, competition for resources, injury or loss of life (Bostedt \& Grahn, 2008; Carter et al., 2012). The management of negative impacts is an important conservation concern as retaliatory killing of wild animals can endanger their populations, and prohibiting retaliation can anger communities sharing space with them (Madden, 2004; Woodroffe et al., 2005). Negative interactions between people and wildlife are often framed as human-wildlife conflict. However, framing human-wildlife relationships predominantly through the lens of conflict can create a strong negative impact on peoples' psyche and influence perceptions of risk from wild animals (Gore et al., 2012).

Peterson et al. (2010) proposed that narratives using the human-wildlife conflict frame tend to represent animals as consciously combating people, dichotomizing humans and nature. The way human-wildlife relationships are framed also has repercussions on how these are interpreted and managed. A biased framing thus provides salience to certain aspects of the relationship, glossing over the nuances that are crucial for wildlife conservation and management (Peterson et al., 2010). Studies have also suggested that human-wildlife conflicts can be split into two components: (1) human-wildlife impacts, and (2) human-human or conservation conflicts that represent the ideological tensions between stakeholders that affect wildlife, for example, preservation of nature vs local livelihoods or human safety (Redpath et al., 2015; Young et al., 2010).

More recently, some researchers have suggested replacing the term human-wildlife conflict, which usually has a negative connotation, with non-negative ones such as human-wildlife coexistence, or human-wildlife interactions. 
By facilitating the recognition of the ambivalence in the attitudes and behaviours of people towards wildlife, these debates have infused some diversity into the narratives, and have highlighted the unfavourable consequences of a predominantly negative framing for conservation (Peterson et al., 2010; Bruskotter \& Fulton, 2012; Carter \& Linnell, 2016; Kansky et al., 2016; Mishra et al., 2016). Nevertheless, few studies have explored the spectrum of human responses to wildlife impacts. Frank (2016) suggested that understanding this spectrum can help practitioners assess the relative intensity and strength of negative, positive and ambivalent responses, enabling them to create specific conservation interventions and strategies. An improved conceptual understanding of the spectrum can also enable us to better assess the factors responsible for peoples' responses.

Previous studies have enumerated several socio-economic, psychological and ecological factors that influence peoples' attitudes towards, and intention to kill, wildlife (St. John et al., 2010; Marchini \& Macdonald, 2012; Kansky et al., 2014). For example, socio-demographic factors such as age, gender, wealth, occupation and education are often correlated with attitudes and behaviours towards wildlife (Kellert, 1985; Peyton et al., 2007; Dickman, 2012; Lindsey et al., 2013). Similarly, descriptive factors such as knowledge of animal behaviour, social norms and taboos about wild animals, and familiarity with the risk posed by wildlife, have also been associated with human responses (McComas, 2006; Marchini \& Macdonald, 2012). However, few studies have attempted to move from a correlational to a mechanistic understanding of factors.

Here, we examine the bias in framing of human-wildlife relationships in the scientific literature and propose a shift towards recognizing the spectrum of human responses to wildlife impacts. We also review and organize the available information on various factors that influence these responses. Our aims are to (1) understand the framing of literature around human-wildlife interactions, (2) develop a typology to assess peoples' responses towards wildlife impacts, and (3) strengthen the understanding of factors that influence responses.

\section{Methods}

We used the ISI Web of Knowledge database to identify articles on human-wildlife interactions, with the keywords 'human-wildlife conflict', OR 'human-wildlife coexistence', OR 'human-wildlife relationship', OR 'human-wildlife interaction', AND 'factors', AND 'drivers', AND 'causes', under 'Topic'. The search yielded a total of 844 results for 1991-2017 (Supplementary Material 1). Of these, the most recent 250 articles were shortlisted for further analysis (i.e. September 2015-July 2017) based on the rationale that these would better reflect the contemporary understanding of human-wildlife relationships. The articles were classified into their predominant frame using a predeveloped typology (Table 1). Two coders began by analysing a portion of the articles $(n=100)$ and established $80 \%$ inter-coder agreement. Disagreements, if any, were resolved by SB.

Based on the results, we characterized a range of human responses towards wildlife impacts. We built our understanding of responses based on prior models of persuasion (e.g. Value-Attitude-Behaviour, Theory of Reasoned Action, Theory of Planned Behaviour; Fishbein \& Ajzen, 1975; Ajzen, 1985; Homer \& Kahle, 1988). We inferred that in our context, attitude and behaviour together comprised a response, considering that previous definitions of tolerance and intolerance comprised both these components. For example, Carter \& Linnell (2016) defined coexistence as a behavioural state where humans and wild animals have learnt to co-adapt with minimal negative impacts on each other. Bruskotter \& Fulton (2012, p. 99) defined tolerance as a 'passive restraint or inaction' on the part of humans up to a threshold of wildlife numbers. Although their concept centred largely around human behaviour, they suggested the approach could also be used to examine human intentions and attitudes.

Treves (2012) pointed out that tolerance and intolerance are states of mind, and therefore emphasis should be placed largely on intentions and attitudes. Similarly, Kansky et al. (2016, p. 138) defined tolerance as 'the ability and willingness of an individual to absorb the extra potential or actual costs of living with wildlife'. The term 'interactions', on the other hand, has been applied more neutrally to illustrate both positive and negative attitudes and behaviours towards wildlife (Redpath et al., 2015). Attitudes represent mental constructs (e.g. thought, feeling) while behaviours represent actions and, together, they have the potential to provide a fuller understanding of human responses to wildlife impacts.

In the next step, we also identified factors influencing human attitudes and behaviours. We made efforts to complement the literature review with an unstructured review to strengthen our understanding of factors. This was done by exploring the key papers and concepts explained in the articles that comprised the review.

\section{Results}

Seventy-one per cent of the 250 articles made use of the human-wildlife conflict frame (Table 1). Within this frame, $89 \%$ pertained to human-wildlife impacts and $11 \%$ described conservation conflicts. Two per cent of the 250 articles discussed coexistence between humans and wildlife, $8 \%$ employed a neutral frame, $1 \%$ invoked both conflict and coexistence with wildlife, and $18 \%$ could not be classified. 
TABLE 1 Typology of frames used to categorize peer-reviewed scientific publications.

\begin{tabular}{ll}
\hline Frame & Meaning \\
\hline Human-wildlife & $\begin{array}{l}\text { Explicit use of the term 'human-wildlife } \\
\text { conflict', mention of human values, atti- } \\
\text { tudes \& behaviours that indicate intoler- } \\
\text { ance or affect wildlife; mention of wildlife } \\
\text { damage or animal behaviour \& ecology } \\
\text { that can precipitate intolerance (e.g. actual } \\
\text { or perceived losses caused by wildlife, im- } \\
\text { pact of animal presence \& movement in } \\
\text { human dominated landscapes, livestock } \\
\text { depredation). Articles that explicitly } \\
\text { framed the issue as human-human or } \\
\text { conservation conflict (i.e. disagreements } \\
\text { about wildlife management) were also } \\
\text { included in this category } \\
\text { Positive human values, attitudes \& beha- } \\
\text { viours indicating tolerance for wildlife (e.g. } \\
\text { cultural values that encourage reverence } \\
\text { towards species that cause damage) } \\
\text { Values, attitudes or behaviours associated } \\
\text { with wildlife that don't explicitly refer to } \\
\text { conistence } \\
\text { conflict or coexistence (e.g. change in } \\
\text { peoples' wildlife value orientation, human } \\
\text { behaviour \& its link to the persistence of } \\
\text { wildlife). Use of the terms 'interaction' or } \\
\text { 'human-animal relations' } \\
\text { Both tolerant \& intolerant human values, } \\
\text { attitudes \& behaviours associated with } \\
\text { wildlife } \\
\text { Articles that did not fit into any of the } \\
\text { above frames (e.g. wildlife disease, } \\
\text { behavioural observations) }\end{array}$ \\
\hline
\end{tabular}

Five types of human responses emerged from our review (Fig. 1): (1) manifested intolerance, in which negative attitudes translated into negative behaviours, (2) latent intolerance, in which negative attitudes did not translate into negative behaviours, (3) neutral or ambivalent attitudes, which did not translate into negative or positive behaviours, (4) appreciation, in which positive attitudes did not translate into positive behaviours, and (5) stewardship, in which positive attitudes translated into positive behaviours.

Upon further review, we found that $27 \%$ of the 250 articles elaborated on factors that influenced human attitudes or behaviours towards wildlife. The review resulted in a list of 55 factors, spanning socio-cultural, economic, psychological and ecological dimensions. We labelled these as proximate factors. Proximate factors could be viewed as variables with a connection to human responses that do not invoke a causal relationship (Alcock, 1975). The proximate factors were grouped into five ultimate factors that represented the potential underlying mechanisms or causes of human response: value orientations, social interactions,

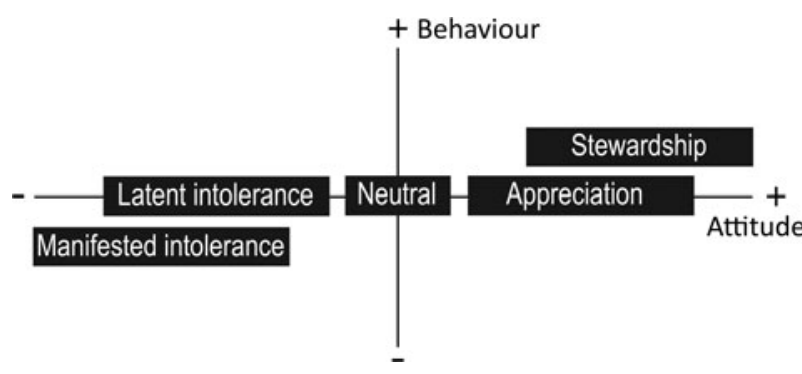

FIG. 1 Visual representation of human response to wildlife impacts. Manifested intolerance comprises responses where both attitude and behaviour are negative towards wildlife. Latent intolerance indicates responses where attitudes are negative, but behaviour is not. Neutral comprises responses where both attitude and behaviour are ambivalent. Appreciation comprises responses where attitudes are positive, but no corresponding positive behaviour can be found. Finally, stewardship indicates responses where both attitude and behaviour are positive.

resource dependence, perceptions of risk, and the nature of interaction with the animal (Table 2, Fig. 2).

\section{Discussion}

\section{Inordinate focus on human-wildlife conflict}

Our findings reiterate that there is a disproportionate emphasis on human-wildlife conflict as a frame and few studies refer to human-human conflict. This may be counterproductive to conservation as it creates a bias in our understanding of peoples' relationship with wildlife (Redpath et al., 2015). It also compounds the real conflict, which usually takes place between communities and the de facto representatives of conservation by assuming wildlife to be deliberately antagonistic towards people (Peterson et al., 2010). It may be more useful to examine people's responses not just in terms of conflict or coexistence but along a spectrum, ranging from negative to positive attitudes and behaviours.

\section{Characterizing human responses to wildlife impacts}

We identified a gradient of attitudinal and behavioural intensity in articles that described human-wildlife relationships, ranging from shades of positive to shades of negative. Most incidents of violent confrontation between people and wildlife, such as retaliatory killing, could be considered examples of manifested intolerance (e.g. Simms et al., 2011; Swanepoel et al., 2015; Hazzah et al., 2017). However, there could be instances where behaviours are negative even though attitudes are positive, such as in situations where an individual is forced to act against his/her preference or beliefs because of the prevailing social 
TABLE 2 Typology of the ultimate factors underlying human responses to wildlife impacts.

\begin{tabular}{ll}
\hline Ultimate factor & Meaning \\
\hline Value orientations & $\begin{array}{l}\text { A preferred organization of beliefs that } \\
\text { mediates an individual's relationship } \\
\text { with the society \& the environment } \\
\text { (Kluckhohn, 1951) } \\
\text { The extent of cooperation, faith \& } \\
\text { confidence between the individual \& } \\
\text { the community, \& between the com- } \\
\text { munity \& the managing agencies in } \\
\text { dealing with wildlife impacts }\end{array}$ \\
The extent of market \& non-market \\
dependence on a resource that could \\
overlap with the needs of wildlife \\
(based on Marshall, 2011) \\
Judgements regarding negative wildlife \\
impacts, based on cognitive \& affective \\
evaluations (based on Slovic, 1987) \\
The context in which humans \& wild- \\
life interact
\end{tabular}

circumstances. Similarly, individuals may succumb to social pressure to relocate a damage-causing animal from their locality despite not feeling strongly about it (Ghosal \& Kjosavik, 2015). Such instances could be classified as manifested intolerance, considering that the ultimate outcome is a negative action towards wildlife.

Latent intolerance can be identified in situations where people's attitudes are negative, but no corresponding negative behaviour can be found (Manfredo \& Dayer, 2004). The intolerance could be a result of unfavourable conditions that have inhibited people from acting negatively, such as perceptions of human incapability or the lack of resources to engage in an intolerant response, or the legal/social implications of engaging in a negative response (e.g. Bhatia et al., 2016). A Buddhist, for example, may feel inclined towards injuring a damage-causing carnivore but may not execute this desire because of legal costs or religious philosophy (Bhatia et al., 2016). This also implies that when the unfavourable conditions are removed, people may, not necessarily, switch from latent to forms of manifested intolerance.

Neutral or ambivalent responses are those where individuals tend not to act either way or are undecided about how they feel towards the wild animal and its impact (Kansky et al., 2014). Appreciation indicates that the individual or community values the existence of the wild animal and chooses to accept the negative impacts even though they may not positively engage with conservation (Dorresteijn et al., 2016). Finally, stewardship comprises situations where the individual or community protects the wild animal even in the face of wildlife damage, owing, perhaps, to the conservation or cultural significance of the species (Bruskotter \& Fulton, 2012; Li et al., 2015).
What affects human responses to wildlife impact?

Similar to Anand \& Radhakrishna (2017), we found that a modest subset of studies on human-wildlife interactions described factors. The 55 factors that we identified were considered proximate factors or correlates because they were pattern-oriented rather than cause-oriented. For example, gender, a proximate factor, may influence human responses to wildlife, but by itself it does not help us understand why a particular gender should have a negative or positive response towards wild animals. The differential engagement of genders with conservation organizations or their varied perceptions of risk could instead be the drivers of their response (Gillingham \& Lee, 1999; Prokop \& Fančovičová, 2010). The five ultimate factors identified in the study were value orientation, social interactions, resource dependence, perceptions of risk and nature of interaction with the animal.

Value orientation can be understood as a preferred organization of beliefs that mediates an individual's relationship with society and the environment (Kluckhohn, 1951). Values enable an individual to choose a conduct that is personally or socially preferable (Rohan, 2000; Vauclair, 2009). Value orientations are affected by ethnicity, religious and cultural beliefs, personal and social norms about the animal in question, a sense of social identity (for example, whether one is a hunter or a farmer), and can be influenced by one's environment (e.g. rural vs urban; Shen et al., 2006; Manfredo, 2008; Marchini \& Macdonald, 2012; Inskip et al., 2016; Koziarski et al., 2016; Pooley, 2016; Amit \& Jacobson, 2017).

Studies have examined how value orientations influence attitudes and behaviour towards nature and wildlife (Rokeach, 1973; Homer \& Kahle, 1988; Ajzen, 1991; Stern \& Dietz, 1994; Natori \& Chenoweth, 2008; Dietsch et al., 2016). Hazzah et al. (2009) pointed out that people's attitude is not defined purely by the economic impacts caused by wildlife but is also affected by the cultural significance of the loss. Cattle hold greater cultural value for the Maasai compared to small livestock (sheep and goats) and therefore lion depredation on cattle provokes greater resentment towards the carnivore (Hazzah et al., 2009).

Social interactions refer to the extent of cooperation, faith and confidence between the individual and the community, and between the community and conservation agencies, when dealing with wildlife impacts. These could have an overarching influence on the way people perceive wildlife in their landscape, who they attribute the ownership of wildlife to, and whether they consider themselves to be marginalized or empowered (Mutanga et al., 2017; Pooley et al., 2017).

The extent of cooperation or conflict over shared resources, a strong social network, and the presence of an environment in which economic and social burdens are shared 


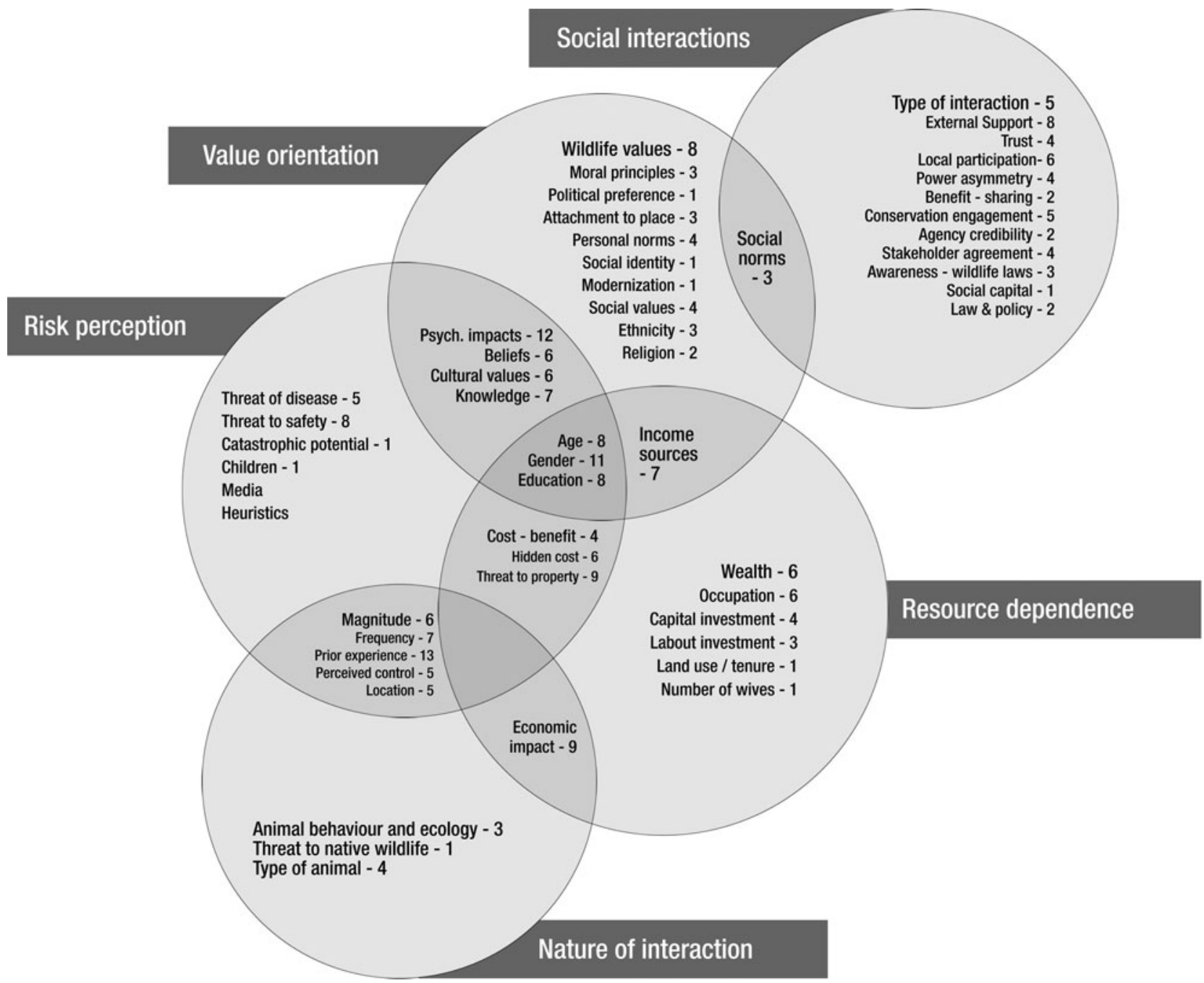

FIG. 2 Factors influencing human responses towards wildlife impacts. Proximate factors (correlates) are listed inside the circles, with the number of times they were mentioned in the articles. The ultimate factors (mechanisms) are in the boxes next to the circles. Except for 'media' and 'heuristics' (see risk perception circle), the remainder were identified in a systematic literature review. Some of the proximate factors influence more than one ultimate factor.

can provide opportunities for people to respond collectively to wildlife impacts (Romañach et al., 2007). Similarly, the nature and the extent of interaction that an individual has with conservation agencies and the extent of consonance between the expectations of the stakeholders involved will determine the level of faith that the community places in the agencies (Zajac et al., 2012; Dorresteijn et al., 2016; Nyhus, 2016; Amit \& Jacobson, 2017; Mishra et al., 2017; Pooley et al., 2017). These interactions are played out against a backdrop of wildlife laws and legal enforcement, political power and media involvement (Bhatia et al., 2013; Rust et al., 2016).

Resource dependence has a direct bearing on the economic and psychological costs of living with wildlife. If a significant proportion of time, labour and money has been invested in a resource that is perceived to be in competition with the needs of wildlife, then an individual is likely to have a more negative response towards wildlife (Gadd, 2005;
Karlsson \& Sjöstrom, 2011; Humle \& Hill, 2016). Furthermore, occupation and wealth are important considerations, and diversification of income sources provides a buffer against loss (Dickman, 2010; Pont et al., 2016). Marshall (2011) further suggested that resource dependence has social, economic and environmental dimensions.

It is also important to understand people's perception of risk from wildlife because this can influence their willingness to coexist with it (Webber \& Hill, 2014). Risk perceptions are the judgements people make when examining and evaluating personal and social threats (Slovic, 1987). Individuals may perceive certain wild animals to be a threat to property or life, or simply be afraid to encounter them (Dorresteijn et al., 2016; Koziarski et al., 2016; Nyhus, 2016). On the other hand, they may feel awe and admiration for the animal despite the costs associated with the interaction (Goldman et al., 2010). The outcome is often 
a trade-off between people's perceptions of the negative impacts of risk and the perceived/expected benefits from it (Banerjee et al., 2013; Kansky et al., 2016). Risk perception has two important dimensions, the cognitive and the affective. The cognitive dimension involves people's assessment of the probability of occurrence of an event and the affective dimension involves the instinctive and spontaneous response of people when they experience it (Riley \& Decker, 2000; Gore et al., 2009). Wildlife damage can also be evaluated in terms of its catastrophic potential, defined as a rare devastating event that can strongly influence peoples' responses (McComas, 2006; Dickman, 2010).

Gore et al. (2007) suggested two predominant types of influences on people's perceptions of risk from wildlife: personal/individual capacity to control, and agency capacity. The former includes factors such as personal volition, perceived probability of exposure to risk, frequency and intensity of exposure, predictability and ability to control the risk, knowledge about the risk, and affect (Dorresteijn et al., 2016; Pont et al., 2016). Agency capacity includes external variables such as trust in the intentions and capabilities of the agency/individuals responsible for mitigation (McComas, 2006; Gore et al., 2007; Earle, 2010).

The nature of interaction with the animal is the setting in which people encounter wildlife. Some specific factors that define people's interactions include the action, target, context and time (Fishbein \& Ajzen, 1975). For instance, what was the impact (action), who caused it (target), where and when did the incident occur (context and time)? Thus, the location of the species, the type of animal, the magnitude of impact, and animal behaviour are important influences (Dorresteijn et al., 2016; Nyhus, 2016). Every interaction need not be negative as there could be situations in which the animal has not caused harm (e.g. it is merely encountered in the landscape) or there could also be instances in which the animal has had a positive impact on the individual (e.g. nature lovers who search for encounters with animals in the wild). The nature of interaction can also affect knowledge and beliefs about the species and thereby influence other ultimate factors such as perceptions of risk, and even value orientation.

Proximate factors such as age, gender, education and the hidden costs of living with damage-causing species work through multiple pathways (Fig. 2). For example, people's perception of risk, their resource dependence and their value orientations may differ depending on their age, gender and level of education (Koziarski et al., 2016; Manfredo et al., 2016). Similarly, the hidden costs of human-wildlife interactions will affect perceptions of risk and resource dependence of individuals (Humle \& Hill, 2016).

The five ultimate factors may also interact with and iteratively influence each other. For example, value orientations may influence perceptions of risk and the type of social interactions within a community and between a conservation agency and the community. Similarly, the nature of interaction with the animal may influence resource dependence as well as perceptions of risk. Resource dependence may have a bearing on risk perceptions and vice-versa. Social interactions may influence perceptions of risk, and vice-versa, at the level of the individual and community.

\section{Conclusion}

Human-wildlife conflict, although a predominant narrative, is not the only form of interaction between people and wild animals. Moving beyond conflict to alternative conceptualizations can affect how we tackle the intellectual and practical challenges of living with wildlife. In this regard, intention and choice can be viewed as playing a key role in influencing people's responses towards wildlife. Based on our findings, we suggest that it may be useful to define tolerance as 'the state of neutral or positive attitude manifested as a neutral to positive behaviour towards wildlife despite their real or potential negative impacts'. Manifested and latent intolerance thus comprise intolerant responses arising from negative attitude or behaviour.

Finally, a move towards exploring the causal linkages or mechanisms influencing human responses could enable practitioners to develop more predictive and proactive models of conservation and management. Our study also aligns with Bruskotter et al. (2017) who proposed that values and risk perceptions were two key mechanisms driving tolerance towards carnivores. Human responses to wildlife differ across individuals and communities, across species, across cultures and over time. Greater coverage of geographies and cultural contexts would help improve our understanding of this important subject.

Globally, interactions between humans and wildlife are expected to increase as suitable wildlife habitats shrink, climate changes and some wild populations recover (Nyhus, 2016). A better knowledge of capacity to tolerate wildlife will, therefore, help in facilitating coexistence between humans and wild animals with minimal repercussions to each other.

Acknowledgements We thank Juliette Young, Yash Veer Bhatnagar, Suri Venkatachalam, Munib Khanyari, and Phalguni Ranjan for their input and support.

Author contributions Study design, fieldwork and data analysis: SB; writing: all authors.

\section{Conflicts of interest None.}

Ethical standards This research did not involve any animal or human subjects, and otherwise abided by the Oryx guidelines on ethical standards. 


\section{References}

Ajzen, I. (1985) From intentions to actions: a theory of planned behavior. In Action-Control: from Cognition to Behavior (eds J. Kuhl \& J. Beckmann), pp. 11-39. Springer, Heidelberg, Germany.

AjZen, I. (1991) The theory of planned behavior. Organizational Behavior and Human Decision Processes, 50, 179-211.

Alcock, J. (ed.) (1975) Animal Behavior: an Evolutionary Approach. Sinauer, Sunderland, USA.

Aмiт, R. \& JACOBSON, S.K. (2017) Understanding rancher coexistence with jaguars and pumas: a typology for conservation practice. Biodiversity and Conservation, 26, 1353-1374.

ANAND, S. \& RADHAKRISHNA, S. (2017) Investigating trends in human-wildlife conflict: is conflict escalation real or imagined? Journal of Asia-Pacific Biodiversity, 10, 154-161.

Banerjee, K., Jhala, Y.V., Chauhan, K.S. \& Dave, C.V. (2013) Living with lions: the economics of coexistence in the Gir forests, India. PLOS ONE, 9, e89708.

Bhatia, S., Athreya, V., Grenyer, R. \& Macdonald, D.W. (2013) Understanding the role of representations of human-leopard conflict in Mumbai through media-content analysis. Conservation Biology, 27, 588-594.

Bhatia, S., Redpath, S.M., Suryawanshi, K. \& Charudutt, M. (2016) The relationship between religion and attitudes toward large carnivores in northern India? Human Dimensions of Wildlife, 22, $30-42$.

Bostedt, G. \& Grahn, P. (2008) Estimating cost functions for the four large carnivores in Sweden. Ecological Economics, 68, 517-524.

Bruskotter, J.T. \& Fulton, D.C. (2012) Will hunters steward wolves? A comment on Treves and Martin. Society and Natural Resources, 25, 97-102.

Bruskotter, J.T., Vucetich, J.A., Manfredo, M.J., Karns, G.R., Wolf, C., Ard, K. et al. (2017) Modernization, risk, and conservation of the world's largest carnivores. BioScience, 67, 646-655.

Carter, N.H. \& Linnell, J.D. (2016) Co-adaptation is key to coexisting with large carnivores. Trends in Ecology \& Evolution, $31,575-578$.

Carter, N.H., Shrestha, B.K., Karki, J.B., Pradhan, N.M.B. \& LIU, J. (2012) Coexistence between wildlife and humans at fine spatial scales. Proceedings of the National Academy of Sciences, 109, 15360-15365.

Dickman, A.J. (2010) Complexities of conflict: the importance of considering social factors for effectively resolving human-wildlife conflict. Animal Conservation, 13, 458-466.

Dickman, A.J. (2012) From cheetahs to chimpanzees: a comparative review of the drivers of human-carnivore conflict and human-primate conflict. Folia Primatologica, 83, 377-387.

Dietsch, A.M., Teel, T.L. \& Manfredo, M.J. (2016) Social values and biodiversity conservation in a dynamic world. Conservation Biology, 30, 1212-1221.

Dorresteijn, I., Milcu, A.I., Leventon, J., Hanspach, J. \& FisCHER, J. (2016) Social factors mediating human-carnivore coexistence: understanding thematic strands influencing coexistence in Central Romania. Ambio, 45, 490-500.

EARLE, T.C. (2010) Trust in risk management: a model-based review of empirical research. Risk Analysis, 30, 541-574.

Fishbein, M. \& Ajzen, I. (eds) (1975) Belief, Attitude, Intention, and Behavior: an Introduction to Theory and Research. Addison-Wesley, Reading, USA.

FrANK, B. (2016) Human-wildlife conflicts and the need to include tolerance and coexistence: an introductory comment. Society and Natural Resources, 29, 738-743.

GADD, M. (2005) Conservation outside of parks: attitudes of local people in Laikipia, Kenya. Environmental Conservation, 32, 50-63.
Ghosal, S. \& KJosAviK, J.D. (2015) Living with leopards: negotiating morality and modernity in western India. Society \& Natural Resources, 28, 1092-1107.

Gillingham, S. \& Lee, P.C. (1999) The impact of wildlife-related benefits on the conservation attitudes of local people around the Selous Game Reserve, Tanzania. Environment Conservation, 26, 218-228.

Goldman, M.J., Roque, J., Pinho, D. \& Perry, J. (2010) Human dimensions of wildlife maintaining complex relations with large cats: Maasai and lions in Kenya and Tanzania. Human Dimensions of Wildlife, 15, 332-346.

Gore, M.L., Kahler, J.S. \& Somers, M. (2012) Gendered risk perceptions associated with human-wildlife conflict: implications for participatory conservation. PLOS ONE, 7, e32901.

Gore, M.L., Knuth, B.A., Curtis, P.D. \& Shanahan, J.E. (2007) Factors influencing risk perception associated with human-black bear conflict. Human Dimensions of Wildlife, 12, 133-136.

Gore, M.L., Wilson, R.S., Siemer, W.F., Hudenko, H.W., Clarke, C.E., HART, P.S. et al. (2009) Application of risk concepts to wildlife management: special issue introduction. Human Dimensions of Wildlife, 14, 301-313.

Hazzah, L., Bath, A., Dolrenry, S., Dickman, A. \& Frank, L. (2017) From attitudes to actions: predictors of lion killing by Maasai warriors. PLOS ONE, 12, e0170796.

Hazzah, L., Mulder, M.B. \& Frank, L. (2009) Lions and warriors: social factors underlying declining African lion populations and the effect of incentive-based management in Kenya. Biological Conservation, 142, 2428-2437.

Homer, P. \& Kahle, L. (1988) A structural equation test of the 'value-attitude-behaviour hierarchy'. Journal of Personality and Social Psychology, 54, 638-664.

Humle, T. \& Hill, C. (2016) People primate interactions: implications for primate conservation. In An Introduction to Primate Conservation (eds A.W. Serge \& A. J. Marshall), pp. 219-240. Oxford University Press, Oxford, UK.

INGOLD, T. (2000) From trust to domination an alternative history of human-animal relations. In The Perception of the Environment: Essays in Livelihood, Dwelling and Skill (ed. T. Ingold), pp. 61-76, Routledge, London, UK.

Inskip, C., Carter, N., Riley, S., Roberts, T. \& MacMillan, D. (2016) Toward human-carnivore coexistence: understanding tolerance for tigers in Bangladesh. PLOS ONE, 11, eo145913.

Kansky, R., Kidd, M. \& Knight, A.T. (2014) Meta-analysis of attitudes toward damage-causing mammalian wildlife. Conservation Biology, 28, 924-938.

Kansky, R., Kidd, M. \& Knight, A.T. (2016) A wildlife tolerance model and case study for understanding human wildlife conflicts. Biological Conservation, 201, 137-145.

Karlsson, J. \& S Jöström, M. (2011) Subsidized fencing of livestock as a means of increasing tolerance for wolves. Ecology and Society, $16,1-10$.

Kellert, S.R. (1985) Public perecptions of predators, particularly the wolf and coyote. Biological Conservation, 31, 167-189.

KLUCKHOHN, C. (1951) Values and value-orientations in the theory of action: an exploration in definition and classification. In Toward a General Theory of Action (eds T. Parsons \& E. Shils), pp. 388-433. Harvard University Press, Cambridge, USA.

Koziarski, A., Kissui, B. \& Kiffner, C. (2016) Patterns and correlates of perceived conflict between humans and large carnivores in Northern Tanzania. Biological Conservation, 199, 41-50.

Lescureux, N. \& Linnell, J.D.C. (2010) Knowledge and perceptions of Macedonian hunters and herders: the influence of species specific ecology of bears, wolves, and lynx. Human Ecology, 387, 389-399. 
Li, J., Wang, D., Yin, H., Zhaxi, D., Jiagong, Z., Schaller, G.B. et al. (2015) Role of Tibetan Buddhist monasteries in snow leopard conservation. Conservation Biology, 28, 87-94.

Lindsey, P.A., Havemann, C.P., Lines, R., Palazy, L., Price, A.E., Retief, T. et al. (2013) Determinants of persistence and tolerance of carnivores on Namibian ranches: implications for conservation on southern African private lands. PLOS ONE, 8, e52458.

Madden, F. (2004) Creating coexistence between humans and wildlife: global perspectives on local efforts to address humanwildlife conflict. Human Dimensions of Wildlife, 9, 247-257.

Manfredo, M.J. (ed.) (2008) Who cares about wildlife? In Social Science Concepts for Exploring Human-Wildlife Relationships and Conservation Issues, pp. 1-27, Springer-Verlag, New York, USA.

Manfredo, M.J. \& Dayer, A.A. (2004) Concepts for exploring the social aspects of human-wildlife conflict in a global context. Human Dimensions of Wildlife, 9, 1-20.

Manfredo, M.J., Teel, T.L. \& Dietsch, A.M. (2016) Implications of human value shift and persistence for biodiversity conservation. Conservation Biology, 30, 287-296.

Marchini, S. \& Macdonald, D.W. (2012) Predicting rancher's intention to kill jaguars: case studies in Amazonia and Pantanal. Biological Conservation, 147, 213-221.

Marshall, N.A. (2011) Assessing resource dependency on the rangelands as a measure of climate sensitivity. Society and Natural Resources, 24, 1105-1115.

McComas, K.A. (2006) Defining moments in risk communication research: 1996-2005. Journal of Health Communication, 11, 75-91.

Mishra, C., Redpath, S.R. \& Suryawanshi, K.S. (2016) Livestock predation by snow leopards: conflicts and the search for solutions. In Snow Leopards: Biodiversity of the World: Conservation from Genes to Landscapes (eds T. McCarthy \& D. Mallon), pp. 59-67. Elsevier, Amsterdam, The Netherlands.

Mishra, C., Young, J.C., Fiechter, M., Rutherford, B. \& Redpath, S.M. (2017) Building partnerships with communities for biodiversity conservation: lessons from Asian mountains. Journal of Applied Ecology, 54, 1583-1591.

Mutanga, C.N., Muboko, N. \& Gandiwa, E. (2017) Protected area staff and local community viewpoints: a qualitative assessment of conservation relationships in Zimbabwe. PLOS ONE 12, e0177153.

Natori, Y. \& Chenoweth, R. (2008) Differences in rural landscape perceptions and preferences between farmers and naturalists. Journal of Environmental Psychology, 28, 250-267.

Nyнus, P.J. (2016) Human-wildlife conflict and coexistence. Annual Review of Environment and Resources, 41, 143-171.

Peterson, M.N., Birckhead, J.L., Leong, K., Peterson, M.J. \& Peterson, T.R. (2010) Rearticulating the myth of human-wildlife conflict. Conservation Letters, 3, 74-82.

Peyton, R.B, Bull, P.A. \& Holsman, R.H. (2007) Measuring the Social Carrying Capacity for Gray Wolves in Michigan. Unpublished report. Michigan State University, Michigan, USA.

Pont, A.C., Marchini, S., Engel, M.T., Machado, R., Ott, P.H., Crespo, E.A. et al. (2016) The human dimension of the conflict between fishermen and South American sea lions in southern Brazil. Hydrobiologia, 770, 89-104.

Pooley, S. (2016) A cultural herpetology of Nile crocodiles in Africa. Conservation \& Society, 14, 391-405.

Pooley, S., Barua, M., Beinart, W., Dickman, A., Holmes, G., Lorimer, J. et al. (2017) An interdisciplinary review of current and future approaches to improving human-predator relations. Conservation Biology, 31, 513-523.
Prokop, P. \& FAnČoviČová, J. (2010) Perceived body condition is associated with fear of a large carnivore predator in humans. Annales Zoologici Fennici, 47, 417-425.

Redpath, S.M., Bhatia, S. \& Young, J. (2015) Tilting at wildlife: reconsidering human-wildlife conflict. Oryx, 49, 222-225.

Riley, S.J. \& Decker, D.J. (200o) Wildlife stakeholder acceptance capacity for cougars in Montana. Wildlife Society Bulletin, 28, 931-939.

Rohan, M.J. (2000) A rose by any name? The values construct. Personality and Social Psychology Review, 4, 255-277.

Rokeach, M. (ed.) (1973) The Nature of Human Values. Free Press, New York, USA.

Romañach, S., Lindsey, P. \& Woodroffe, R. (2007) Determinants of attitudes towards predators in central Kenya and suggestions for increasing tolerance in livestock dominated landscapes. Oryx, 41, 185-195.

Rust, N.A., Tzanopoulos, J., Humle, T. \& MacMillan, D.C. (2016) Why has human-carnivore conflict not been resolved in Namibia? Society and Natural Resources, 29, 1079-1094.

Shen, S.X., ZinN, H. \& WANG, A.Y. (2006) Assessing wildlife value orientations in China: an exploration of the concepts and methodology. In Proceedings of the 2006 Northeastern Recreation Research Symposium (eds R. Burns \& K. Robinson), pp. 468-473, Northern Research Station, New York, USA.

Simms, A., Salahudin, Z.M., Ali, H., Ali, I. \& Wood, T. (2011) Saving threatened species in Afghanistan: snow leopards in the Wakhan Corridor. International Journal of Environmental Studies, $68,299-312$.

Slovic, P. (1987) Perception of risk. Science, 236, 280-285.

St John, A.V.F.A., Edwards-Jones, G.A. \& Jones, J.P.G. (2010) Conservation and human behaviour: lessons from social psychology. Wildlife Research, 37, 658-657.

Stern, P.C. \& Dietz, T. (1994) The value basis of environmental concern. Journal of Social Issues, 50, 65-84.

Swanepoel, L.H., Somers, M.J. \& Dalerum, F. (2015) Functional responses of retaliatory killing versus recreational sport hunting of leopards in South Africa. PLOS ONE, 10, e0125539.

Treves, A. (2012) Tolerant attitudes reflect an intent to steward: a reply to Bruskotter and Fulton. Society \& Natural Resources, 25, 103-104.

Treves, A. \& Naughton-Treves, L. (1999) Risk and opportunity for humans coexisting with large carnivores. Journal of Human Evolution, 36, 275-282.

VAUClair, C. (2009) Measuring cultural values at the individual-level: considering morality in cross-cultural value research. Revista de Administração Mackenzie, 10, 60-83.

Webber, A.D. \& Hill, C.M. (2014) Using Participatory Risk Mapping (PRM) to identify and understand people's perceptions of crop loss to animals in Uganda. PLOS ONE, 9, e102912.

Woodroffe, R., Thirgood, S. \& Rabinowitz, A. (2005) The future of coexistence resolving human-wildlife conflicts in a changing world. In People and Wildlife, Conflict or Coexistence? (eds R. Woodroffe, S. Thirgood \& A. Rabinowitz), pp. 388-405, Cambridge University Press, Cambridge, UK.

Young, J.C., Marzano, M., White, R.M., Mccracken, D.I., Redpath, S.M., Carss, D.N. et al. (2010) The emergence of biodiversity conflicts from biodiversity impacts: characteristics and management strategies. Biodiversity and Conservation, 19, 3973-3990.

Zajac, R.M., Bruskotter, J.T., Wilson, R.S. \& Prange, S. (2012) Learning to live with black bears: a psychological model of acceptance. The Journal of Wildlife Management, 76, 1331-1340. 